\title{
A novel multicolor immunostaining method using ethynyl deoxyuridine for analysis of in situ immunoproliferative response
}

\author{
Yusuke Kitazawa $^{1} \cdot$ Hisashi Ueta $^{1} \cdot$ Thomas Hünig $^{2} \cdot$ Yasushi Sawanobori $^{1}$ • \\ Kenjiro Matsuno ${ }^{1}$
}

Accepted: 30 April 2015 / Published online: 15 May 2015

(C) The Author(s) 2015. This article is published with open access at Springerlink.com

\begin{abstract}
Immune responses are generally accompanied by antigen presentation and proliferation and differentiation of antigen-specific lymphocytes (immunoproliferation), but analysis of these events in situ on tissue sections is very difficult. We have developed a new method of simultaneous multicolor immunofluorescence staining for immunohistology and flow cytometry using a thymidine analogue, 5-ethynyl-2'-deoxyuridine (EdU). Because of the small size of azide dye using click chemistry and elimination of DNA denaturation steps, EdU staining allowed for immunofluorescence staining of at least four colors including two different markers on a single-cell surface, which is impossible with the standard 5-bromo-2'-deoxyuridine method. By using two rat models, successfully detected parameters were the cluster of differentiation antigens including phenotypic and functional markers of various immune cells, histocompatibility complex antigens, and even some nuclear transcription factors. Proliferating cells could be further sorted and used for RT-PCR analysis. This method thus enables functional in situ time-kinetic analysis of immunoproliferative responses in a distinct domain of the lymphoid organs, which are quantitatively confirmed by flow cytometry.
\end{abstract}

Electronic supplementary material The online version of this article (doi:10.1007/s00418-015-1329-z) contains supplementary material, which is available to authorized users.

\footnotetext{
Kenjiro Matsuno

kenjiro@dokkyomed.ac.jp

1 Department of Anatomy (Macro), Dokkyo Medical University, 880 Kitakobayashi, Mibu, Tochigi 321-0293, Japan

2 Institute for Virology and Immunobiology, University of Würzburg, Würzburg, Germany
}

Keywords EdU $\cdot$ Multicolor immunofluorescence staining $\cdot$ Rat $\cdot$ Immunohistology $\cdot$ Flow cytometry Immunoproliferative response $\cdot \mathrm{T}$-cell dendritic cell cluster

\section{Introduction}

Immune responses induce activation and clonal expansion of antigen-specific lymphocytes with active DNA synthesis for cell division. Dendritic cells (DCs) undergo a crucial interaction with lymphocytes as professional antigenpresenting cells in the distinct domain of the secondary lymphoid organs. DCs form a cluster with antigen-specific lymphocytes and induce immunoproliferation, i.e., their differentiation and proliferation within the cluster (Matsuno et al. 1989; Saiki et al. 2001; Ueta et al. 2008). Therefore, in situ examination of phenotype and functional molecules of cycling cells and cellular interactions with DCs or stromal cells during the immune response should provide crucial information for understanding immunity in health and diseases.

We have long studied immunoproliferative responses in situ by using a multicolor immunoenzyme staining analysis (Matsuno et al. 1989, 2010; Saiki et al. 2001; Ueta et al. 2008) for a thymidine analogue, 5-bromo- $2^{\prime}$-deoxyuridine (BrdU), and other parameters. However, because enzymedeveloped color dyes tend to interfere with the following immunostaining step, only two-color analysis prior to BrdU staining could be performed at best and detection of two different markers on a single-cell surface was very difficult. Immunofluorescence staining has an advantage, because fluorescent dyes do not interfere with each other and four-color staining is possible by a standard protocol. However, BrdU immunofluorescence staining is also problematic, because it requires DNA denaturation steps 
for exposing antigen epitopes by strong acid or heating, resulting in decreased intensity of other fluorescent dyes. Therefore, a new method other than BrdU staining has been needed for a long time.

Although flow cytometry (FCM) enables quantitative analysis of multiple parameters of a proper cell subset, it requires single-cell suspensions and therefore cannot delineate the in situ localization or cellular interaction. In contrast, although immunohistology is the most practical method for in situ analysis, quantitative analysis of the immune response in the tissue sections is time consuming and not easy. Accordingly, parallel analysis of both immunohistology and FCM using one sample should provide good information about the immune response.

Recently, a thymidine analogue, EdU (5-ethynyl-2'deoxyuridine), was described as a replacement for BrdU to directly measure de novo DNA synthesis of S-phase cycling cells using click chemistry (Salic and Mitchison 2008). Click chemistry is a method of covalently coupling an azide with an alkyne. Detection of EdU relies on the copper (I)-catalyzed click reaction with an azide-modified fluorescent dye to form a stable triazole ring. Because of the small size of the azide dye, no harsh denaturation steps are needed to gain access to the DNA (Salic and Mitchison 2008). Previous studies reported that EdU could be used for immunohistology (Salic and Mitchison 2008) or FCM (Diermeier-Daucher et al. 2009) as a thymidine analogue. Accordingly, EdU staining holds the potential to be applied in multicolor immunofluorescence including proliferating cells and double-membrane staining of a single cell, which is impossible with the standard BrdU method. In neuroscience research, a few publications report using triple immunohistogical staining for two neuronal peptide antigens and EdU (Guo et al. 2009). Because the tissues are prefixed with paraformaldehyde (PFA) and stable intracellular peptide antigens are targets of immunostaining, this method is not applicable for double-membrane staining of the cluster of differentiation (CD) antigens, which are mostly labile and easily denatured or masked by aldehyde fixatives.

In the present study, by applying our original multicolor immunoenzyme (Saiki et al. 2001; Ueta et al. 2008) and immunofluorescence (Sawanobori et al. 2014) staining methods, we have tried to develop a new method of simultaneous multicolor immunofluorescence staining using EdU for up to four colors for immunohistology and up to three colors for FCM. Two models for assessing the in vivo proliferative response of immune cells were examined. The first is the administration of a CD28 superagonist (CD28SA), reported to preferentially expand forkhead box P3 (Foxp3) gene-expressing naturally occurring regulatory T-cells (nTregs) (Beyersdorf et al. 2005). The second is the one-way graft-versus-host reaction (GvHR) by the transferring of parental congeneic T-cells to $\mathrm{F}_{1}$ hybrid rats (Matsuno et al. 2010). Here we show that lymphocyte markers, histocompatibility complex antigens, cell adhesion molecules, and even nuclear transcription factors in addition to EdU can be detected simultaneously by this method.

\section{Materials and methods}

\section{Animals}

Inbred male Lewis $\left(\mathrm{RT}_{1} \mathrm{~A}^{\mathrm{l}} \mathrm{B}^{\mathrm{l}}\right)$ and $\mathrm{PvG} / \mathrm{c}\left(\mathrm{RT} 1 \mathrm{~A}^{\mathrm{c}} \mathrm{B}^{\mathrm{c}}\right)$ rats were purchased by SLC Co. (Shizuoka, Japan). Congeneic $\mathrm{PVG} / \mathrm{c}-\mathrm{RT} 7^{\mathrm{b}} / \mathrm{OlaHsd}\left(\mathrm{RT}_{1} \mathrm{~A}^{\mathrm{c}} \mathrm{B}^{\mathrm{c}} \mathrm{RT} 7^{\mathrm{b}}\right)$ rats and $\left(\mathrm{PvG} / \mathrm{c} \times\right.$ Lewis) $\mathrm{F}_{1}$ hybrid rats were bred and maintained in the Laboratory Animal Center for Research (Dokkyo Medical University). All animals were reared under specific pathogen-free conditions and used at 8-10 weeks of age. Animal handling and care were approved by the Dokkyo Medical University Animal Experiments Committee and were in accordance with the Dokkyo University's Regulations for Animal Experiments and with Japanese Governmental Law (No. 105). No studies involving human participants are reported here.

\section{Antibodies and reagents}

Monoclonal antibodies (mAbs) and labeled secondary antibodies (Abs) used for immunohistology and FCM (FACSCalibur, BD Biosciences, Franklin Lakes, NJ, USA) analyses are listed in Table 1. Some mAbs were purified from culture supernatants and coupled to fluorescein isothiocyanate, PerCP/Cy5.5 (Innova Bioscience Ltd, Cambridge, UK), Alexa Fluor ${ }^{\circledR} 350$ (Alexa-350), 488, 594, 647, or 680 (Molecular Probes, Eugene, OR, USA) in house. To detect EdU, the Click-iT ${ }^{\circledR}$ EdU Alexa-488, -594, or -647 Flow kit for FCM or imaging was used (Click-iT kit, Life Technologies Corporation, Carlsbad, CA, USA).

\section{Experimental design}

For the first experiment, Lewis rats received intravenous injection of a CD28 superagonist mAb (CD28SA, clone JJ316: $0,0.25,0.5,1 \mathrm{mg} / 300 \mathrm{~g}$ body weight), and the spleens were collected 3 days later. In the second experiment, one-way systemic GvHR was induced by intravenous injection of T-cells of congeneic $\mathrm{PVG} / \mathrm{c}-\mathrm{RT} 7^{\mathrm{b}}$ rats into $\left(\mathrm{PvG} / \mathrm{c} \times\right.$ Lewis) $\mathrm{F}_{1}$ hybrid rats, and the spleens were collected 1 and 2 days after injection. For a source of donor T-cells, thoracic duct lymphocytes $\left(5.0 \times 10^{7}\right.$ cells/rat $)$ were used after thoracic duct cannulation, as reported 
Table 1 Antibodies used in this study

\begin{tabular}{|c|c|c|c|}
\hline \multicolumn{4}{|l|}{ Primary Ab } \\
\hline Antigen & Isotype & Clone & Conjugate $^{\text {Source }}$ \\
\hline $\operatorname{TCR} \alpha \beta$ & Mouse $\operatorname{IgG}_{1}$ & $\mathrm{R} 73$ & Unconjugated $^{\mathrm{h}}$, Alexa- $647^{\mathrm{k} \#}$, PerCP-Cy5. $5 \mathrm{I}^{\mathrm{\#}}$ \\
\hline $\mathrm{CD} 4$ & Mouse $\operatorname{IgG}_{2 \mathrm{a}}$ & OX38 & Unconjugated $^{\mathrm{a}}$ \\
\hline $\mathrm{CD} 8 \beta$ & Mouse $\mathrm{IgG}_{1}$ & 341 & Unconjugated $^{\mathrm{b}}$, Alexa- $647^{\mathrm{b}}$ \\
\hline CD11c & Mouse $\operatorname{IgG}_{2 \mathrm{a}}$ & $8 \mathrm{~A} 2$ & Unconjugated $^{\mathrm{a}}$ \\
\hline $\mathrm{CD} 25$ & Mouse $\operatorname{IgG}_{1}$ & OX39 & Unconjugated $^{\mathrm{h}}$, fluorescein isothiocyanate $\left(\right.$ FITC) ${ }^{\mathrm{b}}$ \\
\hline CD103 ( $\alpha$ E integrin) & Mouse $\mathrm{IgG}_{1}$ & OX62 & Unconjugated $^{\mathrm{h}}$, Alexa- $594^{\#}$ \\
\hline CD205 & Mouse $\operatorname{IgG}_{1}$ & HD83 & Unconjugated $^{\mathrm{b}}$, Alexa-594 ${ }^{\#}$ \\
\hline Donor lymphocyte CD45 $\left(\mathrm{RT}^{\mathrm{b}}\right)$ & Mouse $\mathrm{IgG}_{1}$ & HIS41 & Unconjugated ${ }^{\mathrm{j}}$, Alexa- $488^{\#}$, Alexa-647 \\
\hline Host MHCII (RT1B $)$ & Mouse $\mathrm{IgG}_{1}$ & OX3 & Unconjugated $^{\mathrm{h}}$, Alexa- $647^{\#}$ \\
\hline Helios & Hamster IgG & $22 \mathrm{~F} 6$ & PerCP/Cy $5.5^{b}$ \\
\hline Foxp3 & Rat $\operatorname{IgG}_{2 \mathrm{a}}$ & FJK-16s & Biotin $^{\mathrm{d}}$, Alexa- $647^{\mathrm{d}}$ \\
\hline BrdU & Rat $\operatorname{IgG}_{2 \mathrm{a}}$ & BU1/75 & Unconjugated $^{\text {a }}$, Alexa- $647^{\#}$ \\
\hline Type IV collagen & Rabbit IgG & Polyclonal & Unconjugated $^{\mathrm{i}}$ \\
\hline
\end{tabular}

Secondary Ab and streptavidin

\begin{tabular}{lll}
\hline Product & Conjugate & Source \\
\hline Goat Ig anti-mouse IgG & Alkaline phosphatase & $g$ \\
Donkey Ig anti-rat IgG & Alkaline phosphatase & $e$ \\
Goat $\mathrm{F}\left(\mathrm{ab}^{\prime}\right)_{2}$ anti-rabbit IgG & Horseradish peroxidase & $c$ \\
Goat Ig anti-mouse IgG & Alexa-350, Alexa-594, Alexa-680 & $f$ \\
Donkey Ig anti-rabbit IgG & Aminomethylcoumarin (AMCA) & $e$ \\
Streptavidin & Alexa-488 & $f$ \\
\hline
\end{tabular}

\# Own conjugation

${ }^{a}$ AbD serotec

b Biolegend

c Cappel

${ }^{\mathrm{d}}$ Ebioscience

e Jackson immunoresearch

${ }^{\mathrm{f}}$ Life Technologies Corporation

g Sigma

h ECACC

${ }^{\mathrm{i}}$ Generously provided by Dr. Y. Sado

j Generously provided by Dr. F. Kroese

${ }^{k}$ Alexa: Alexa Flour $^{\circledR}$

${ }^{1}$ The tandem conjugate in Peridinin Chlorophyll Protein Complex and Cyanine 5.5

(Zhou et al. 2008). In both experiments, recipient rats received an intravenous injection of a mixture of equivalent moles of BrdU $(6 \mathrm{mg} / 200 \mathrm{~g}$ body weight, Sigma-Aldrich Japan, Tokyo) and EdU (5 mg/200 g body weight, Life Technologies Corporation) in phosphate-buffered saline (PBS) $1 \mathrm{~h}$ before killing. To avoid masking or loss of labile $\mathrm{CD}$ antigens by aldehyde fixatives, fresh cryosections without prefixation were employed. General anesthesia during animal procedures was provided using isoflurane (Mylan Inc., Tokyo, Japan) supplied by an isoflurane vaporizer (SN-487-OT; Shinano Manufacturing, Tokyo, Japan).

\section{Splenic lymphocyte isolation}

The harvested spleens were injected with Collagenase D (1 mg/mL, Roche Diagnostics GmbH, Mannheim, Germany) and DNase I (400 U/mL, Roche Diagnostics GmbH) in $3 \mathrm{~mL}$ Hank's buffered salt solution (HBSS) containing $5 \%$ fetal calf serum, $1.2 \mathrm{mM} \mathrm{CaCl} \cdot 2 \mathrm{H}_{2} \mathrm{O}$, and $0.8 \mathrm{mM}$ $\mathrm{MgSO}_{4} \cdot 7 \mathrm{H}_{2} \mathrm{O}$ and were digested under gentle stirring for $30 \mathrm{~min}$ at $37{ }^{\circ} \mathrm{C}$ in a $\mathrm{CO}_{2}$ incubator (MCO-18AIC; Sanyo, Osaka, Japan). The collagenase digestion was stopped by adding $0.5 \mathrm{M}$ EDTA solution and five volumes of cold 
PBS. The isolated splenocytes were filtered through a $200-\mu \mathrm{m}$ nylon mesh and washed twice in PBS with $0.2 \%$ bovine serum albumin (PBS-BSA) by centrifugation (himac CF16RX; Hitachi Ltd, Tokyo, Japan) at $280 \times g$ for $10 \mathrm{~min}$ at $4{ }^{\circ} \mathrm{C}$. The splenic lymphocyte fraction was isolated in an OptiPrep discontinuous density gradient (15 and $11.5 \%$, Axis-Shield, Oslo, Norway) by centrifugation at $600 \times g$ for $24 \mathrm{~min}$ at room temperature (RT). With this approach, the upper layer cells of the $15 \%$ OptiPrep were mainly lymphocytes; interface cells between 15 and $11.5 \%$ OptiPrep were macrophages, and DCs. The lymphocyte fractions were washed once by centrifugation at $440 \times g$ for 10 min at $4{ }^{\circ} \mathrm{C}$ and used for FCM.

\section{Flow cytometric analysis}

Splenic lymphocytes at $10^{6}$ cells/100 $\mu$ L PBS-BSA were incubated for $30 \mathrm{~min}$ at $4{ }^{\circ} \mathrm{C}$ with an optimal concentration of purified mouse $\mathrm{mAbs}$ to anti-rat $\mathrm{CD}$ antigens diluted and washed three times with PBS-BSA by centrifugation at $350 \times \mathrm{g}$ for $5 \mathrm{~min}$. The cells were incubated with PerCP/ Cy5.5-conjugated anti-mouse IgG secondary antibody (Biolegend, San Diego, CA, USA) for $30 \mathrm{~min}$ at $4{ }^{\circ} \mathrm{C}$ in PBS-BSA with $1 \%$ normal rat serum and rinsed three times with PBS-BSA. Cells then were incubated for $1 \mathrm{~h}$ at $4{ }^{\circ} \mathrm{C}$ with normal mouse $\operatorname{IgG}(20 \mu \mathrm{g} / \mathrm{mL})$ in PBS-BSA for blocking additional mouse antibody binding. The next step was incubation with a purified second $\mathrm{mAb}$ directly conjugated with Alexa-647 for $30 \mathrm{~min}$ at $4{ }^{\circ} \mathrm{C}$, followed by a wash. The EdU staining was performed at the final step. The cells were permeabilized with a permeabilization buffer set (00-5523-00, eBioscience San Diego, CA, USA) overnight $(\mathrm{O} / \mathrm{N})$ at $4{ }^{\circ} \mathrm{C}$ for intracellular staining and washed. EdU was visualized using the Click-iT kit for FCM according to the manufacturer's instructions. Cells were analyzed by FCM (FACSCalibur) with CellQuest Pro software (BD Biosciences).

In case of Foxp3 staining, the second mAb was omitted, and the cells were first permeabilized in the same manner as for EdU staining. Then, the cells were incubated with Alexa-647-conjugated anti-mouse/rat Foxp3 mAb (FJK$16 \mathrm{~s}$, eBioscience) in permeabilization buffer for $30 \mathrm{~min}$ at $4{ }^{\circ} \mathrm{C}$ and washed at least three times with the same buffer. The EdU staining was performed without the permeabilization step.

In the first experiment, $\mathrm{TCR} \alpha \beta^{+} \mathrm{CD} 25^{\text {high }} \mathrm{EdU}^{+}$or $\mathrm{EdU}^{-}$ cells were further isolated by FACSAria (BD Biosciences) sorting. Then Foxp3 message was examined in both cell groups by reverse transcription polymerase chain reaction (RT-PCR, Model TP600, Takara Bio, Inc., Shiga, Japan) at 30 cycles (for $10 \mathrm{~s}$ at $98{ }^{\circ} \mathrm{C}, 30 \mathrm{~s}$ at $60{ }^{\circ} \mathrm{C}$, and $60 \mathrm{~s}$ at $72{ }^{\circ} \mathrm{C}$ ). Primers were as follows: Foxp3, forward primer,
5'-CGG GAG AGT TTC TCA AGC AC-3'; reverse primer, 3'-GGA GCT CTT GTC CAC TGA GG-5'; GAPDH (glyceraldehyde-3-phosphate dehydrogenase: Internal control), forward primer, 5'-AGA CAG CCG CAT CTT CTT GT-3'; and reverse primer, $3^{\prime}$-CTT GCC GTG GGT AGA GTC AT- $5^{\prime}$.

\section{Cryosectioning and pretreatment}

We applied the processing method for the immunoenzyme (Saiki et al. 2001; Ueta et al. 2008) and immunofluorescence (Sawanobori et al. 2014) staining methods in our laboratory to the EdU immunofluorescence staining. Fresh cryosections were cut using a LEICA CM1850 (Leica Microsystems, Ontario, Canada) and were processed as described in the "Recommended protocols."

\section{Multicolor fluorescence immunohistology using EdU}

For both experiments, three- to four-color immunofluorescent staining was performed as precisely described in supplemental online materials for either phenotype (TCR $\alpha \beta$, etc.) of proliferating cells (EdU), nuclear transcription factor (Foxp3), tissue frameworks (type IV collagen), and DCs (CD103, etc.) in the spleen cryosections. Multicolor images were captured using an Axioskop2 Plus fluorescent microscope (Carl Zeiss, Jena, Germany) with an AxioCam MRm camera and AxioVision software (Carl Zeiss). Filters used were Filter Set 49 for Alexa-350, 17 for Alexa-488, 32 for Alexa-647 or -680 (Carl Zeiss), and XF407 for Alexa-594 (Omega Optical, Brattleboro, VT, USA), respectively. This filter combination had negligible crossing over of emitted lights between filters. We assigned pseudocolors to each channel to make merged images more comprehensible by maximizing contrast using AxioVision software (Carl Zeiss).

\section{Multicolor enzyme immunohistology using BrdU}

For the second experiment, the spleen cryosections were triple enzyme-immunostained for donor lymphocytes (RT7 ${ }^{\mathrm{b}}$ congeneic marker, blue), type IV collagen (brown), and proliferating cells (BrdU, red) as previously described (Saiki et al. 2001; Ueta et al. 2008).

\section{Correlation of EdU and BrdU in cell proliferation analysis}

To confirm that EdU-positive $\left(\mathrm{EdU}^{+}\right)$cells and BrdU ${ }^{+}$cells were the same proliferating cell population, triple immunofluorescent staining for type IV collagen, EdU, and BrdU was performed. After the blocking solution, sections were 
incubated for $1 \mathrm{~h} \sim \mathrm{O} / \mathrm{N}$ at $\mathrm{RT}$ with a rabbit anti-mouse type IV collagen $\mathrm{Ab}$ and washed. Sections were incubated with aminomethylcoumarin (AMCA)-conjugated anti-rabbit IgG for $1 \mathrm{~h}$ and washed. Then, EdU was stained using the Click-iT ${ }^{\circledR}$ kit. For DNA denaturation, sections were treated for $10 \mathrm{~min}$ at $89^{\circ} \mathrm{C}$ by a Microwave processor (MI77, Azumaya, Tokyo, Japan) with a Retrivagen kit (BD Biosciences) and cooled to RT. After being washed and blocked, sections were incubated with Alexa-647-conjugated anti-BrdU mAb for $1 \mathrm{~h}$ at RT. Sections were mounted with coverslips and were examined under a fluorescence microscope.

\section{Results}

\section{EdU staining correlates well with BrdU staining in immunohistology}

The Click-iT ${ }^{\circledR}$ kit resulted in intense and clear EdU staining with a low signal-to-noise ratio for all fluorochromes tested: Alexa-488, -594, and -647. The protocol from the manufacturer was easy and reproducible and applicable not only for FCM but also for immunohistology.

The immunostaining of the spleen in the first experiment showed a massive proliferative response in the white pulp at 3 days after CD28SA stimulation (Supplementary Fig. 1). Double immunofluorescent staining for EdU and BrdU showed superimposition of $\mathrm{EdU}^{+}$nuclei on almost all $\mathrm{BrdU}^{+}$nuclei (Supplementary Fig. 1). To note, in some cells, the intensities of both stainings were different where BrdU ${ }^{\text {high }}$ cells are EdU ${ }^{\text {low }}$ or vise versa, which was also shown previously (Salic and Mitchison 2008).

\section{Parallel analysis of FCM and immunohistology}

When the proliferative response of $\mathrm{TCR} \alpha \beta^{+}, \mathrm{CD} 4^{+}$, $\mathrm{CD} 8 \beta^{+}$, and $\mathrm{CD} 25^{+}$cells was examined by FCM of the spleen cells in the same rats, the absolute numbers of $\mathrm{EdU}^{+} \mathrm{TCR} \alpha \beta^{+}, \mathrm{EdU}^{+} \mathrm{CD}^{+}, \mathrm{EdU}^{+} \mathrm{CD} 8 \beta^{+}$, and $\mathrm{EdU}^{+} \mathrm{CD} 25^{+}$cells increased in a dose-dependent fashion relative to $\mathrm{CD} 28 \mathrm{SA}$ (Fig. 1a, b). In contrast, $\mathrm{EdU}^{+} \mathrm{CD} 8 \beta^{+}$ cells were much fewer in number than other $\mathrm{EdU}^{+}$cells (Fig. 1b).

Multicolor fluorescence immunohistology of rats receiving $0.5 \mathrm{mg}$ of CD28SA showed that many $\mathrm{TCR} \alpha \beta^{+}, \mathrm{CD} 4^{+}$, and $\mathrm{CD}_{2} 5^{+}$cells but only a few $\mathrm{CD} 8 \beta^{+}$cells had EdU ${ }^{+}$ nuclei in the T-cell area of the splenic white pulp, i.e., the periarterial lymphocyte sheath (PALS) (Fig. 1c). Therefore, EdU staining enables the parallel examination of the proliferative response of activated cells both quantitatively by FCM and qualitatively by immunohistology of tissue sections.

\section{Simultaneous detection of a transcription factor and cycling $S$-phase cells}

We next examined the nuclear transcription factors of Tregs, i.e., Foxp3 (Kitazawa et al. 2009) and Helios (Gottschalk et al. 2012), with the expectation that expression would increase with CD28SA stimulation. At day 3 after $0.5 \mathrm{mg}$ CD28SA stimulation, the FCM analysis of the spleen cells showed a fivefold to tenfold increase in $\mathrm{TCR} \alpha \beta^{+}, \mathrm{CD}^{+}$, or $\mathrm{CD} 25^{+} \mathrm{EdU}^{+}$cells expressing Foxp3 compared to PBS-injected control (Fig. 2a). The absolute number of proliferating Tregs increased in a dose-dependent fashion with CD28SA (Fig. 2b). In addition, some $\mathrm{EdU}^{+}$Foxp $3{ }^{+} \mathrm{CD} 25^{+}$Tregs also expressed Helios (not shown). Furthermore, by using this sample, $\mathrm{TCR} \alpha \beta^{+} \mathrm{CD} 25^{\text {high }} \mathrm{EdU}^{+}$or $\mathrm{EdU}^{-}$Tregs could be isolated by FACSAria sorting, and Foxp3 message could be detected in both cell groups by RT-PCR (Fig. 3a).

Multicolor fluorescence immunohistology of the same spleen showed that many CD25 $5^{\text {high }}$ cells with Foxp $3^{+} \mathrm{EdU}^{+}$ nuclei were more frequently observed in the PALS than in the control (Fig. 3b). The results were in agreement with those of the FCM study.

We thus could directly demonstrate proliferation and expression of some transcription factors of Tregs by FCM and immunohistology. Foxp $3^{+} \mathrm{EdU}^{+}$proliferating Tregs could be further isolated and used for RT-PCR analysis.

\section{Simultaneous detection of two different surface markers of cycling S-phase cells}

We used a GvHR model to examine whether EdU can be used or not for analysis of proliferating cells in the immune response. First, three-color enzyme immunostaining was performed to confirm our previously published findings (Matsuno et al. 2010; Zhou et al. 2008). The injected donor cells were detected by staining a congeneic CD45 marker $\left(\mathrm{RT}^{\mathrm{b}}\right.$ ) by His41 mAb (Kampinga et al. 1990), type IV collagen, and BrdU. One day after injection, $\mathrm{RT}^{\mathrm{b}+}$ donor lymphocytes were detected in the host splenic PALS, as confirmed by type IV collagen staining, and a few of them were $\mathrm{BrdU}^{+}$(Fig. 4a). On day 2, many donor lymphocytes became $\mathrm{BrdU}^{+}$(Fig. 4a). This finding represents proliferation of activated donor lymphocytes undergoing GvHR.

Second, four-color immunofluorescence staining of the same rat spleens was performed. As expected, many $\mathrm{EdU}^{+} \mathrm{RT}^{\mathrm{b}+}$ donor lymphocytes were TCR $\alpha \beta^{+}$(Fig. 4b) and $\mathrm{CD}^{+}$(not shown), but only a few of them were $\mathrm{CD}^{+} \beta^{+}$(Fig. 4b). The FCM analysis of the spleen cells of the same rats showed that $\mathrm{TCR} \alpha \beta^{+}$and $\mathrm{CD} 4^{+}$donor T-cells were mostly $\mathrm{EdU}^{-}$on day 1 but that many of them became $\mathrm{EdU}^{+}$on day 2 (Fig. $4 \mathrm{c}, \mathrm{d}$ ). In contrast, $\mathrm{CD} 8 \beta^{+}$ donor T-cells were very few in number and rarely became 
a
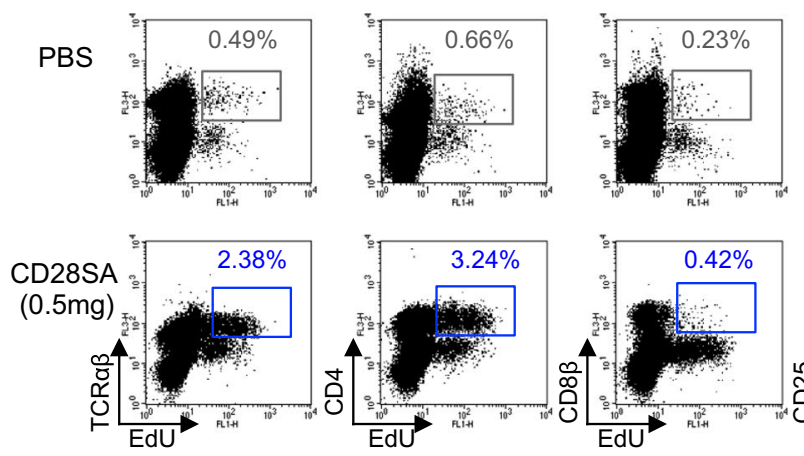

C
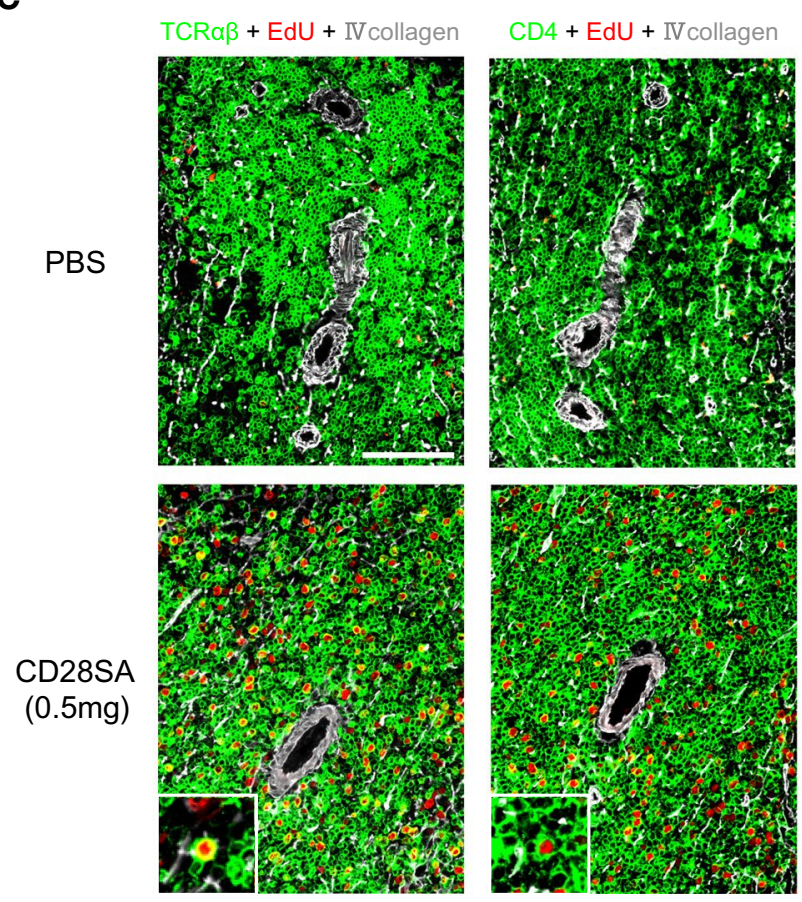

b
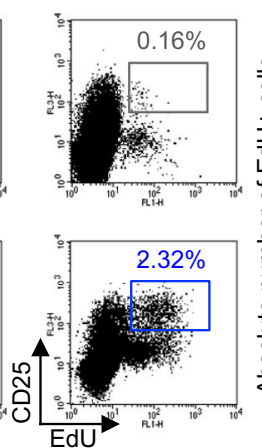
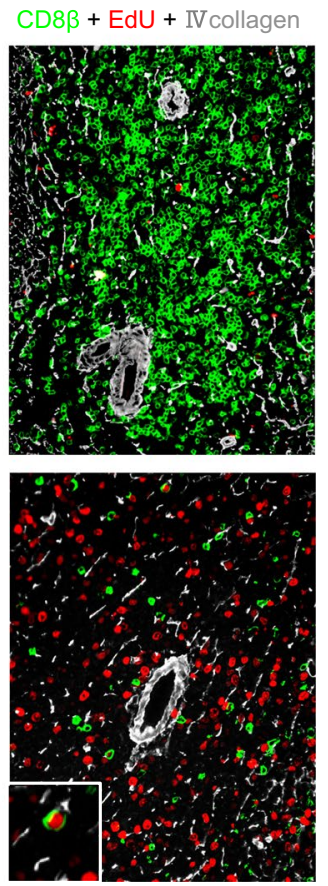

CD25 + EdU + IVcollagen
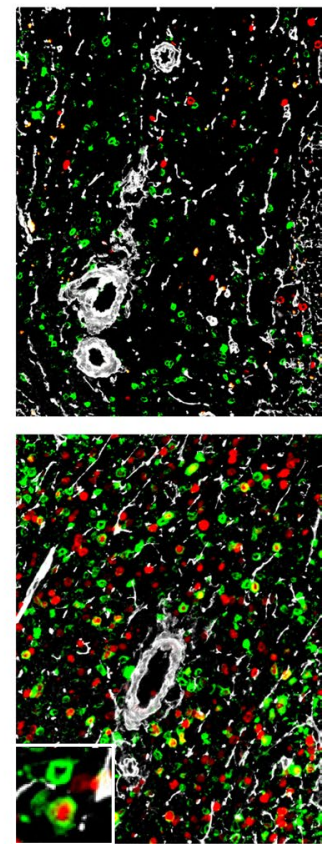

Fig. 1 Assessment of proliferating lymphocytes in the spleen activated by CD28SA. a FCM analysis of the splenic lymphocytes for lymphocyte markers and EdU at day 3 after CD28SA injection $(0.5 \mathrm{mg} / \mathrm{rat})$. Note increase in $\mathrm{TCR} \alpha \beta^{+}, \mathrm{CD} 4^{+}$, or $\mathrm{CD} 25^{+} \mathrm{EdU}^{+}$cells but not $\mathrm{CD} 8 \beta^{+} \mathrm{EdU}^{+}$cells compared to control. b Dose response of splenic lymphocytes to CD28SA. Absolute number of $\mathrm{EdU}^{+}$proliferating cells with different lymphocyte markers/spleen, showing $1.0 \mathrm{mg}$ group induces the highest response. $\mathbf{c}$ Triple immunofluores- cent staining for lymphocyte markers (indirect staining with Alexa680-conjugated anti-mouse IgG, green), EdU (Alexa-594-conjugated azide, red) and type IV collagen (indirect staining with AMCAconjugated anti-rabbit IgG, white). Day 3 after CD28SA injection $(0.5 \mathrm{mg} / \mathrm{rat})$. Pseudocolors were assigned using AxioVision software. Scale bar $100 \mu \mathrm{m}$. The splenic PALS area with the central arteries is depicted by type IV collagen. Proliferating cells with different markers are shown as green cells with red nuclei (inset of lower panel)
$\mathrm{EdU}^{+}$on day 2 (Fig. 4c, d), confirming the immunohistological finding (Fig. 4b).

\section{Analysis of cellular interactions between two different cell types}

For analysis of cellular interactions in vivo, direct observation of different types of cells being activated through the interactions is crucial. We previously reported that early cluster formation of donor T-cells with host DCs and the proliferative response of these T-cells within the cluster represent the direct pathway of allosensitization in the allograft response (Saiki et al. 2001; Ueta et al. 2008). To reveal either two different surface markers of cycling S-phase cells or host DCs in the cluster, four-color immunofluorescence staining of the same rat spleens on day 2 was performed.

Concerning cluster-forming donor lymphocytes, many $\mathrm{EdU}^{+} \mathrm{RT}^{\mathrm{b}+}{ }^{\mathrm{TCR}} \alpha \beta^{+}$cycling S-phase donor T-cells were seen to form clusters with host class II major histocompatibility complex antigen-positive $\left(\mathrm{MHCII}^{+}\right)$putative DCs 

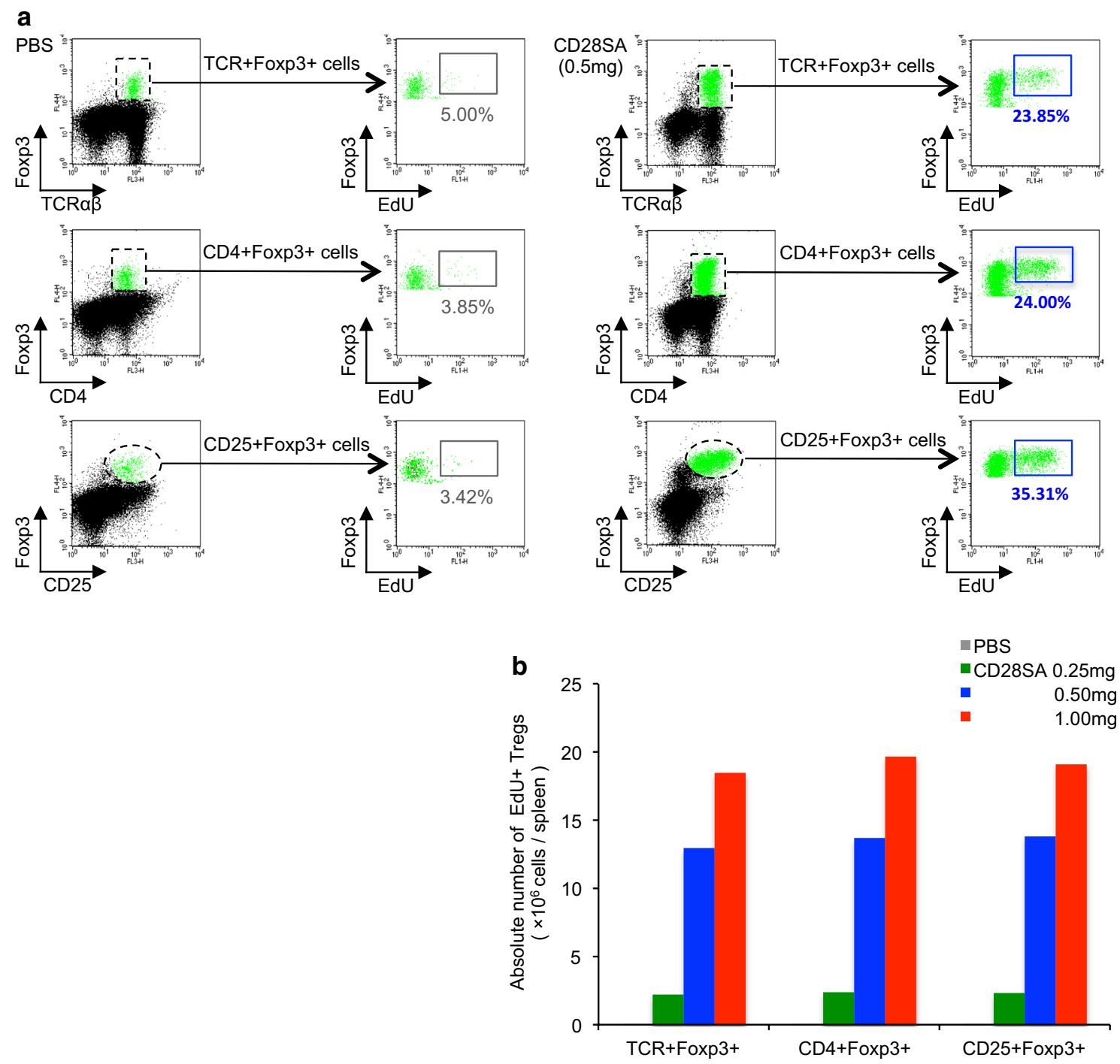

Fig. 2 FCM for proliferating Tregs induced by CD28SA. a Threecolor FCM analysis of the splenic lymphocytes for lymphocyte markers, Treg transcription factor (Foxp3), and EdU at day 3 after CD28SA injection $(0.5 \mathrm{mg} / \mathrm{rat})$. b Dose response of Foxp $3^{+}$Tregs

with different markers to CD28SA. Absolute number of EdU ${ }^{+}$proliferating Tregs with different lymphocyte markers/spleen, showing $0.5-1.0 \mathrm{mg}$ induces an intense response

in the PALS (Fig. 5a). In contrast, $\mathrm{EdU}^{+} \mathrm{CD} 8 \beta^{+}$donor T-cells were few and did not form clusters with host putative DCs (Fig. 5b). As for the cluster-forming host $\mathrm{MHCII}^{+}$ cells with $\mathrm{EdU}^{+}$cells, some of them possessed DC markers, such as CD205 (Park et al. 2012), CD103, or CD11c (Fig. 6), indicating that these cells were at least partly host DCs. Concerning the cluster-forming host DCs with $\mathrm{EdU}^{+}$donor lymphocytes, cluster formation between host $\mathrm{MHCII}^{+} \mathrm{CD} 205^{+}$or $\mathrm{CD} 103^{+}$DCs and $\mathrm{EdU}^{+} \mathrm{RT} 7^{\mathrm{b}+}$ donor lymphocytes could be demonstrated (Fig. 7).

The results show that EdU staining enables analysis of cellular interactions in situ by simultaneous visualization of different surface markers of cycling S-phase cells or stromal cells.

\section{Discussion}

In this study, by taking advantage of the unique characteristics of EdU, we have developed a new method that allows examination of immune responses with lymphocyte proliferation both functionally and morphologically in situ as well as in vitro. The four-color immunofluorescence staining using EdU for immunohistology or three-color for FCM and the simultaneous application of both staining approaches for one target tissue have not been reported so far. EdU staining correlated well with BrdU staining of spleen sections activated by the CD28SA stimulation (Supplementary Fig. 1). This outcome confirms previous indications that EdU can be used for immunohistology of cycling 
a
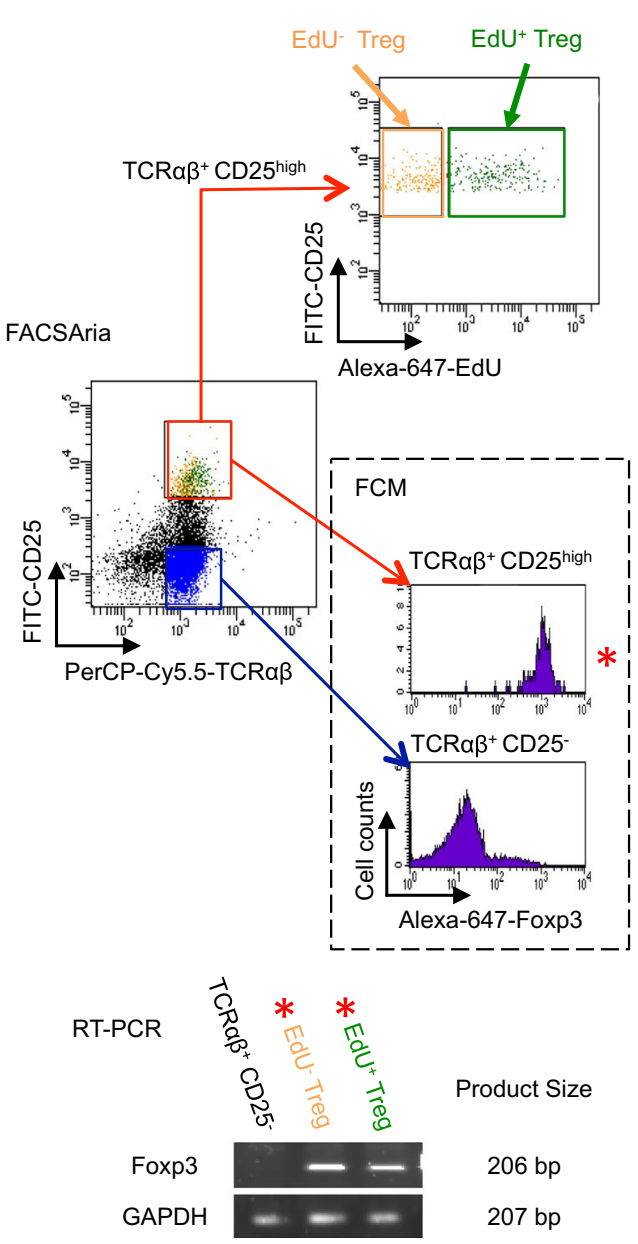

b
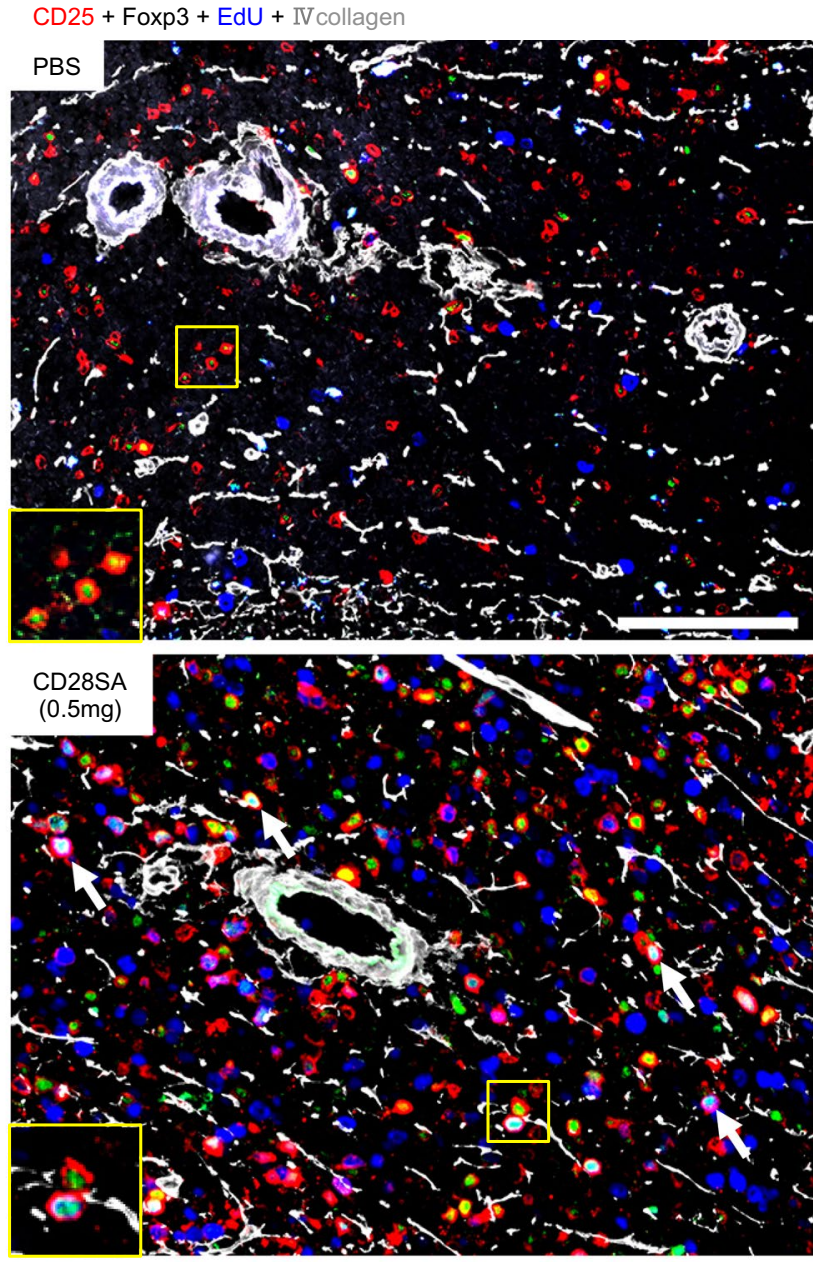

EdU- CD25+ Foxp3+ Treg

EdU+ CD25+ Foxp3- cells

EdU+ CD25+ Foxp3+ Treg
Fig. 3 FACSAria sorting and immunohistological analysis for proliferating Tregs. a RT-PCR analysis of TCR $\alpha \beta^{+} \mathrm{CD} 25^{\text {high }} \mathrm{Foxp}^{+}{ }^{+} \mathrm{EdU}^{+}$ or EdU ${ }^{-}$Tregs isolated by FACSAria sorting. b Four-color immunofluorescent staining for CD25 (indirect staining with Alexa-680-conjugated anti-mouse $\mathrm{IgG}$, red), Foxp3 (Biotin-labeled mAb plus Alexa488-conjugated streptavidin, green), EdU (Alexa-594-conjugated

S-phase cells as a thymidine analogue (Salic and Mitchison 2008). The presence of some $\mathrm{BrdU}^{\text {high }} \mathrm{EdU}^{\text {low }}$ or BrdU ${ }^{\text {low- }}$ EdU ${ }^{\text {high }}$ cells might be due to the competitive uptake of both nucleosides by a single cell.

\section{Simultaneous detection in situ of two different markers of cycling S-phase cells}

Because of the small size of the detection reagent and elimination of DNA denaturation steps, EdU staining allows the azide, blue), and type IV collagen (indirect staining with AMCAconjugated anti-rabbit IgG, white). Pseudocolors were assigned using AxioVision software. Splenic PALS area at day 3 after CD28SA injection $(0.5 \mathrm{mg} / \mathrm{rat})$. Proliferating $\mathrm{CD} 25^{+} \mathrm{Foxp}^{+}$Tregs are depicted as red cells with light blue nuclei (inset and white arrows) in the CD28SA spleen but few in the control spleen. Scale bar $100 \mu \mathrm{m}$ multicolor immunofluorescence of at least four colors including two different markers on a single-cell surface, which has been impossible by the standard BrdU method. In this way, any cells of specific phenotypes can be identified in situ, e.g., T-cells (Fig. 1), Tregs (Fig. 3), donor T-cells (Fig. 4b), and host DCs (Figs. 6, 7) and their functional molecules can be further studied, e.g., expression of CD25 (Fig. 3) and CD103 (Figs. 6, 7). Because these markers are mostly labile surface $\mathrm{CD}$ antigens, our method using fresh cryosections can provide a superb staining result for these antigens compared to the 


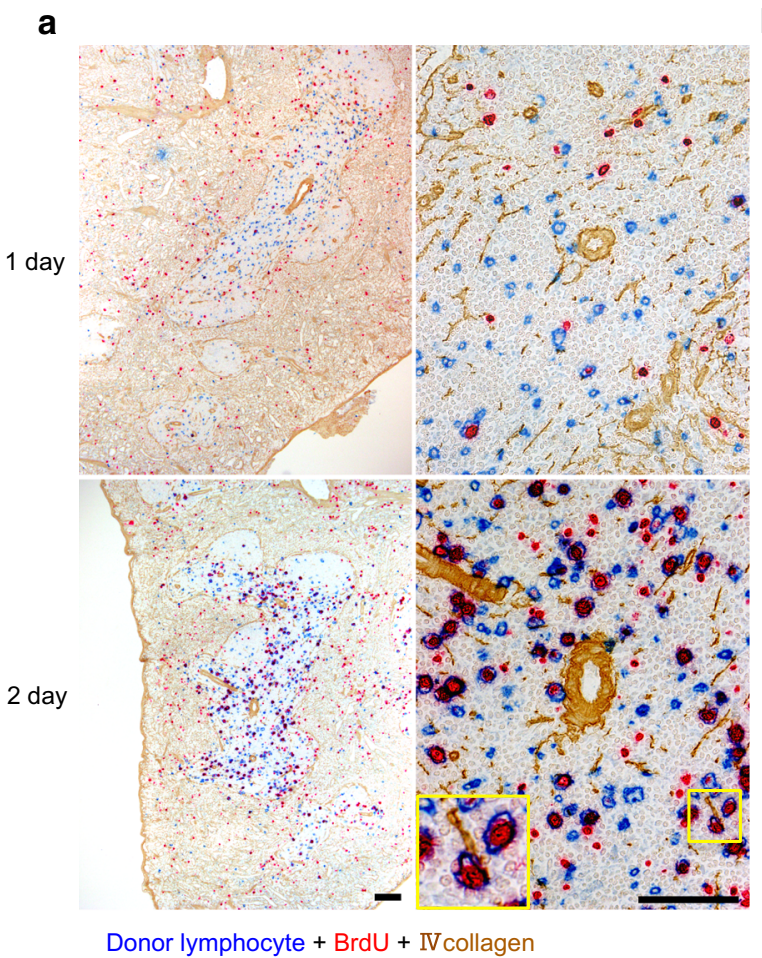

Donor lymphocyte + BrdU + IVcollagen b 2 day

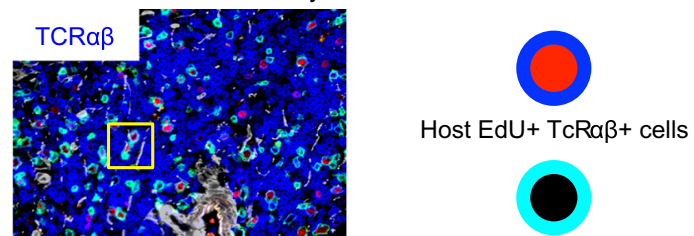

Donor EdU- TCRa $\beta+$ cells

Donor EdU+ TCRaß+ cells

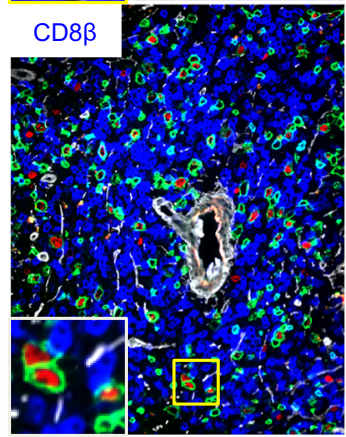

Donor lymphocyte + mAb + EdU + IVcollagen
C

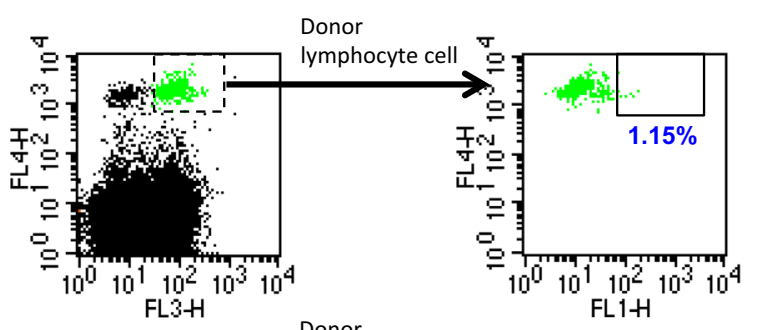

d

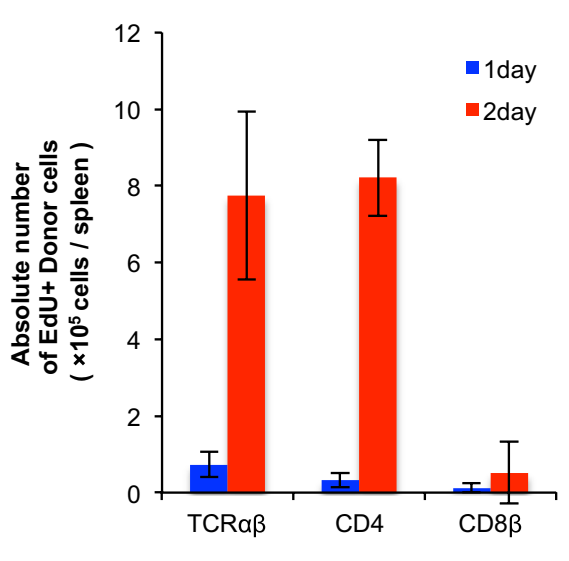

Fig. 4 Migration and proliferation of donor lymphocytes in GvHR. a Three-color immunoenzyme staining of the spleen after GvHR induction for donor lymphocytes (RT7 ${ }^{\mathrm{b}+}$, blue), type IV collagen (brown), and BrdU (red). Note migration of donor lymphocytes into the PALS on day 1 and their proliferation on day 2 (inset). Scale bar $100 \mu \mathrm{m}$. b Four-color immunofluorescence staining of the spleen for TCR $\alpha \beta$ or $\mathrm{CD} 8 \beta$ (Alexa-647-conjugated $\mathrm{mAb}$, blue), donor lymphocytes (indirect staining with Alexa-488-conjugated anti-mouse IgG, green), type IV collagen (indirect staining with AMCA-conjugated anti-rabbit IgG, white), and EdU (Alexa-594-conjugated azide, red). Pseudoc-

prefixation method used in the neuroscience field (Guo et al. 2009). Furthermore, some nuclear transcription factors can be simultaneously detected, e.g., Foxp3 in $\mathrm{CD} 4{ }^{+} \mathrm{CD} 25^{\text {high }} \mathrm{EdU}^{+}$ cells (Fig. 3). These results show that this method enables olors were assigned using AxioVision software. Merged images are explained schematically in the right side of the panels. Note proliferation of TCR $\alpha \beta^{+}$(light blue cell with red nucleus, inset) but not $\mathrm{CD} 8 \beta^{+}$donor cells (no light blue cell with red nucleus, inset). Scale bar $100 \mu \mathrm{m}$. c FCM for donor lymphocytes, TCR $\alpha \beta$, and EdU of the spleen, showing increase in proliferating $\mathrm{TCR} \alpha \beta^{+}$donor T-cells on day 2. d Absolute number of EdU ${ }^{+}$proliferating donor lymphocytes with different lymphocyte markers/spleen, showing TCR $\alpha \beta^{+} \mathrm{CD} 4^{+}$ donor T-cells actively proliferate on day 2

functional time-kinetic analysis of immune responses of a certain cell type in a distinct domain of the lymphoid organs. An example is the Treg proliferative response occurring in the splenic PALS at day 3 after CD28SA stimulation (Figs. 2, 3). 

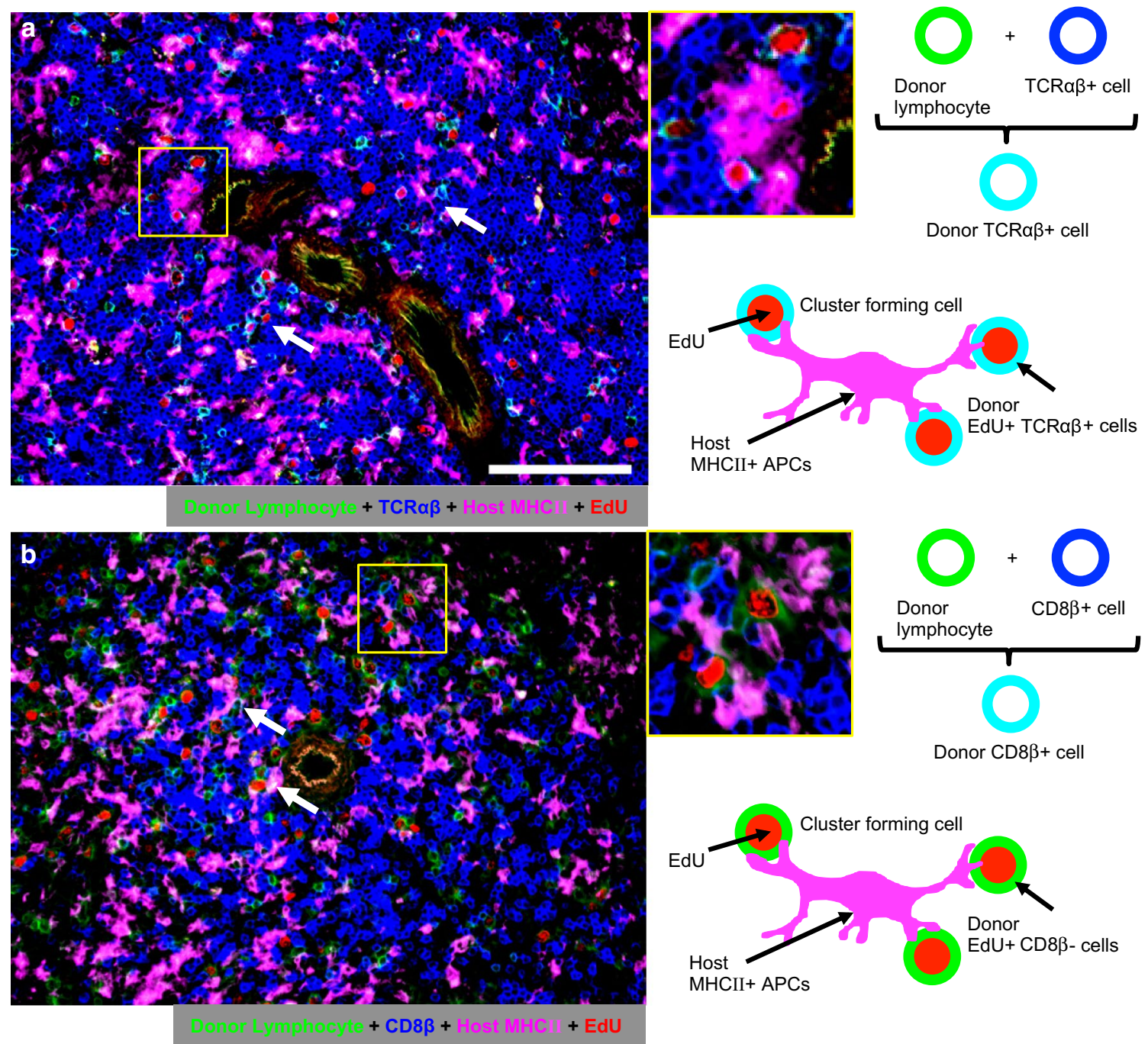

Fig. 5 Phenotype of proliferating donor lymphocytes that cluster with host $\mathrm{MHCII}^{+}$putative DCs (APCs). Four-color immunofluorescence staining of the spleen of day 2 after GvHR induction for $\mathrm{TCR} \alpha \beta$ or CD8 $\beta$ (Alexa-647-conjugated mAb, blue), donor lymphocytes (Alexa-488-conjugated mAb, green), host MHCII (indirect staining with Alexa-350-conjugated anti-mouse IgG, magenta), and EdU (Alexa-594-conjugated azide, red). Pseudocolors were assigned

\section{In situ analysis of cellular interactions between two cell types}

Concerning the cluster formation between proliferating T-cells and DCs, the standard three-color immunoenzyme staining using BrdU could at best show only clusters of $\mathrm{BrdU}^{+}$cells and host $\mathrm{MHCII}^{+}$putative DCs (Saiki et al. 2001; Ueta et al. 2008). In the GvHR study, we could identify cluster formation between $\mathrm{EdU}^{+} \mathrm{CD}^{+}$donor T-cells and host $\mathrm{MHCII}^{+}$putative DCs (Fig. 5), and the latter were further confirmed as host DCs, being either $\mathrm{CD} 103^{+}$, CD205 ${ }^{+}$(Figs. 6, 7), or CD11c ${ }^{+}$(Fig. 6). Therefore, the using AxioVision software. Scale bar $100 \mu \mathrm{m}$. Merged images are explained schematically in the right side of the panels. Note proliferation of $\mathrm{TCR} \alpha \beta^{+}$(a light blue cell with red nucleus, inset and white arrows) but not $\mathrm{CD} 8 \beta^{+}$donor T-cells (b green cell with red nucleus is $\mathrm{CD} 8 \beta^{-} \mathrm{EdU}^{+}$, inset and white arrows) that cluster with host $\mathrm{MHCII}^{+}$ cells

present method could allow analysis of cellular interactions in situ more precisely by the simultaneous visualization of different specific markers or functional molecules of cycling S-phase cells or stromal cells.

This cluster represents a site of antigen presentation by DCs to T-cells and proliferation and differentiation of activated T-cells (Saiki et al. 2001; Ueta et al. 2008), making it one of the most crucial structures when the afferent limb of the immune response occurs. Therefore, we propose that EdU staining can provide an exclusive method for clarifying essential cellular interactions in the immune response in vivo. 

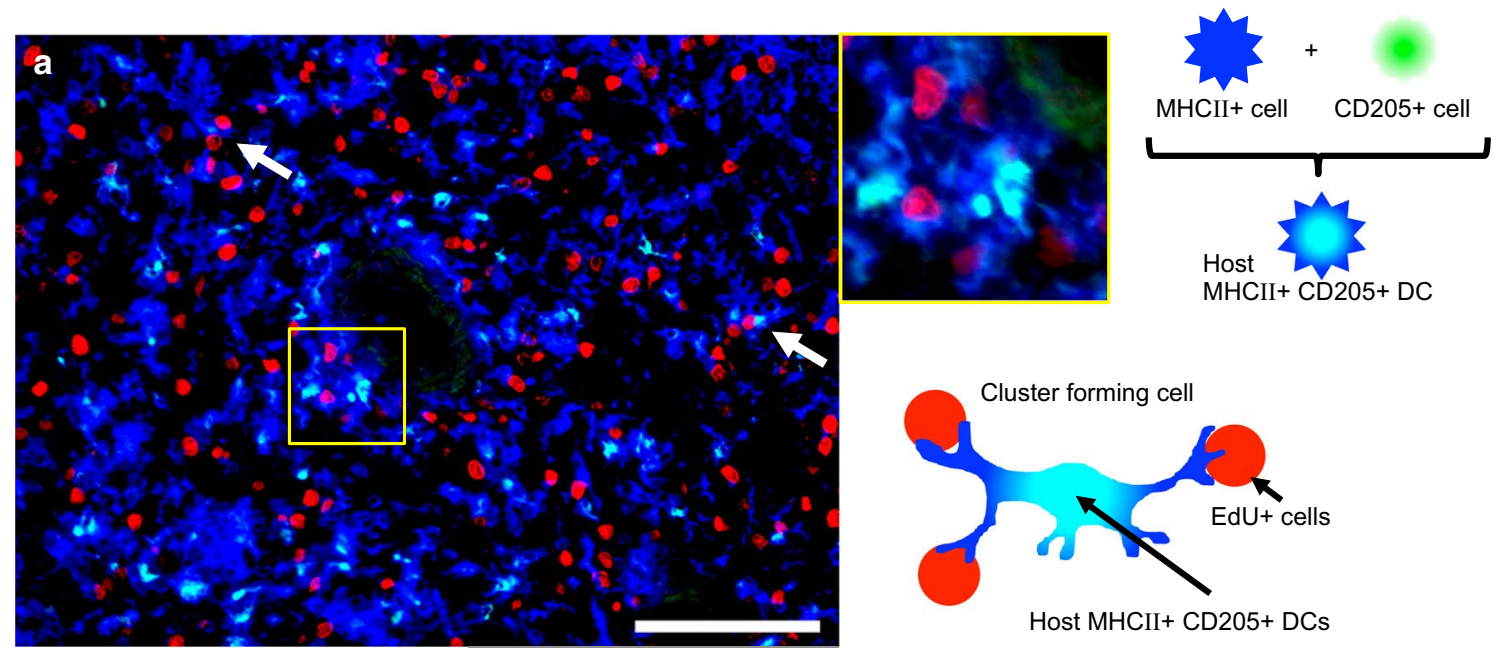

+ Host MHCII + EdU

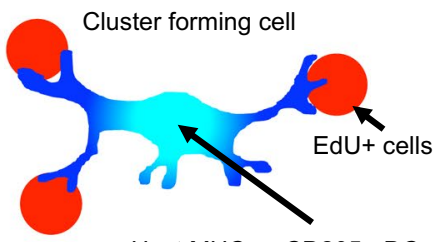

Host MHCII+ CD205+ DCs
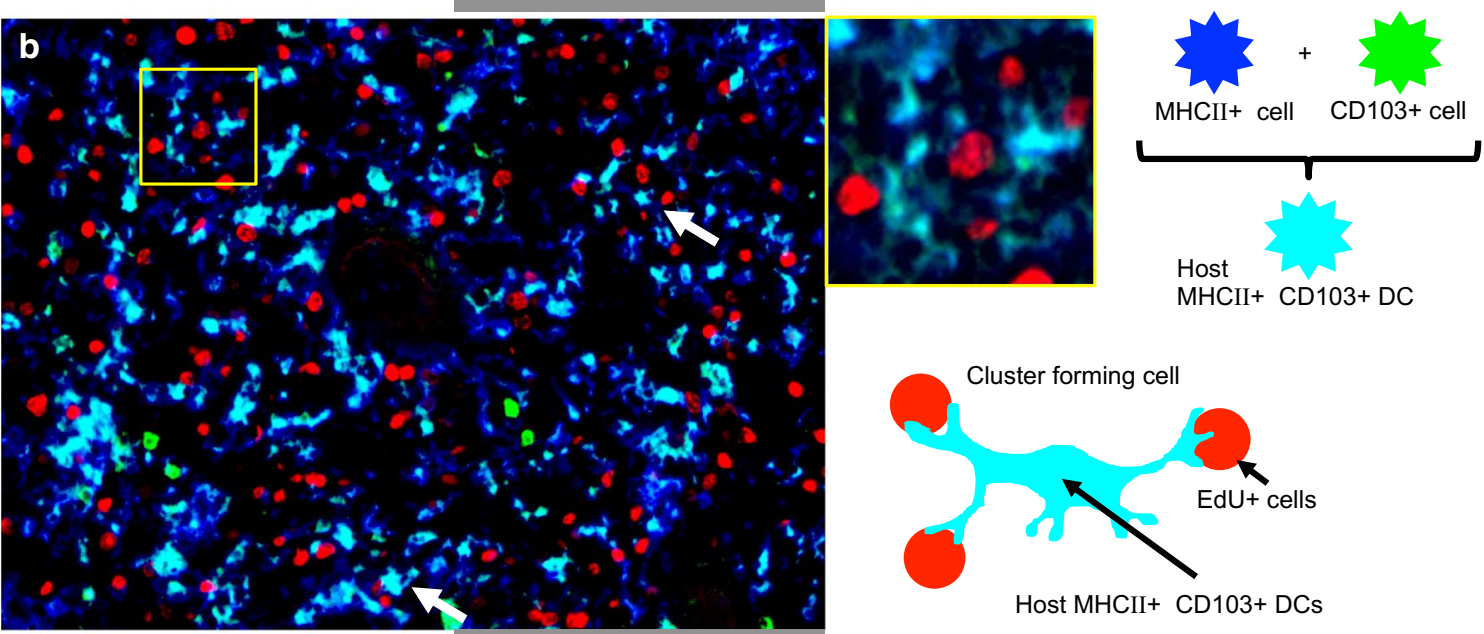

MHCII+ CD103+ DC

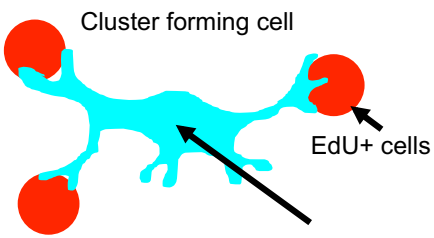

Host MHCII+ CD103+ DCs

+ Host MHCII + EdU
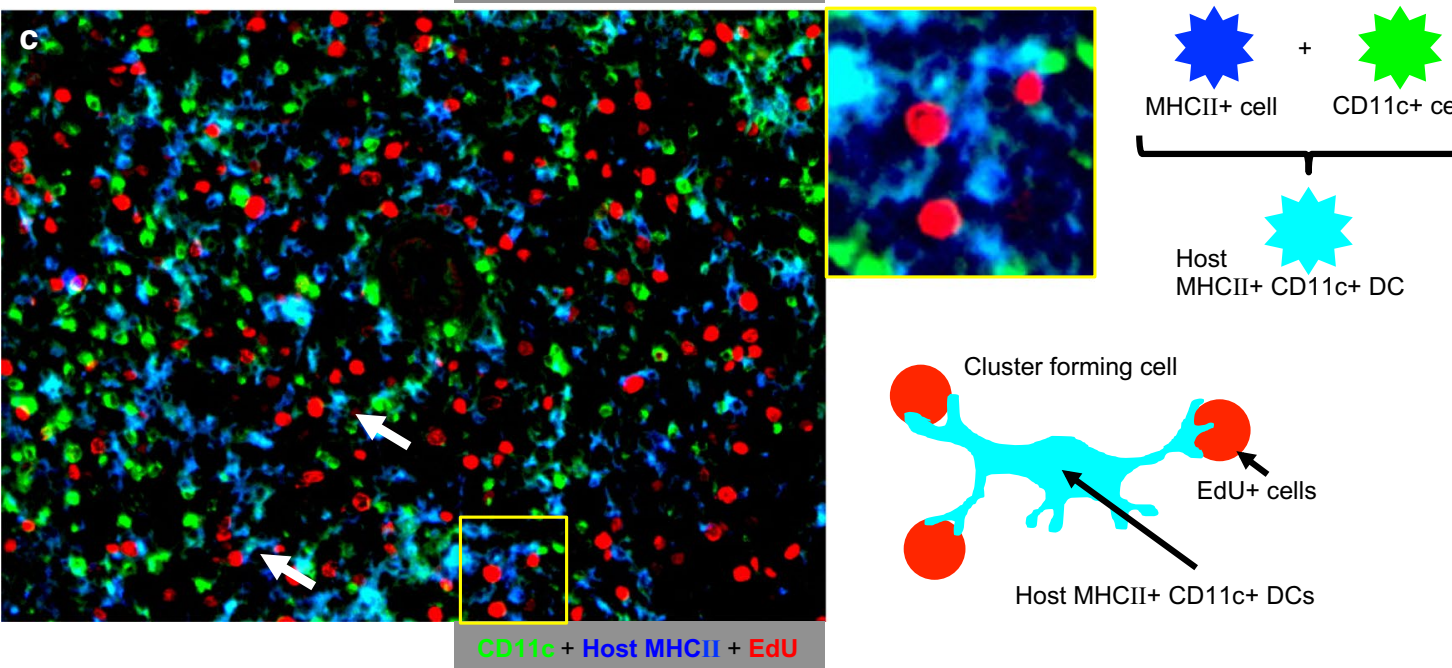

$\mathrm{MHCII}+$ cell $\quad \mathrm{CD} 11 \mathrm{c}+\mathrm{cel}$

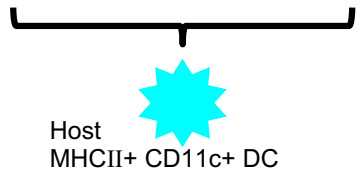

Cluster forming cell

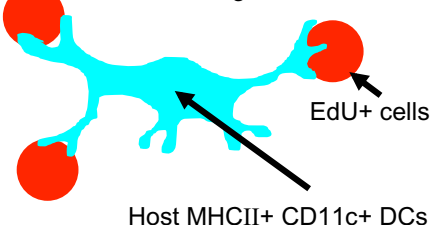

Fig. 6 Phenotype of host $\mathrm{MHCII}^{+}$putative DCs that cluster with proliferating cells. Three-color immunofluorescence staining of the spleen of day 2 after GvHR induction for host MHCII (Alexa647-conjugated $\mathrm{mAb}$, blue), CD205, CD103, or CD11c (indirect staining with Alexa-594-conjugated anti-mouse $\mathrm{IgG}$, green), and EdU (Alexa-488-conjugated azide, red). Pseudocolors were assigned using AxioVision software. Scale bar $100 \mu \mathrm{m}$. Merged images are explained schematically in the right side of the panels. Note host $\mathrm{MHCII}^{+}$cells that cluster with proliferating cells (red nuclei) are either $\mathrm{CD}_{205^{+}}(\mathbf{a}), \mathrm{CD}_{103}{ }^{+}(\mathbf{b})$, or $\mathrm{CD} 11 \mathrm{c}^{+}(\mathbf{c})$ (light blue, inset and white arrows) 

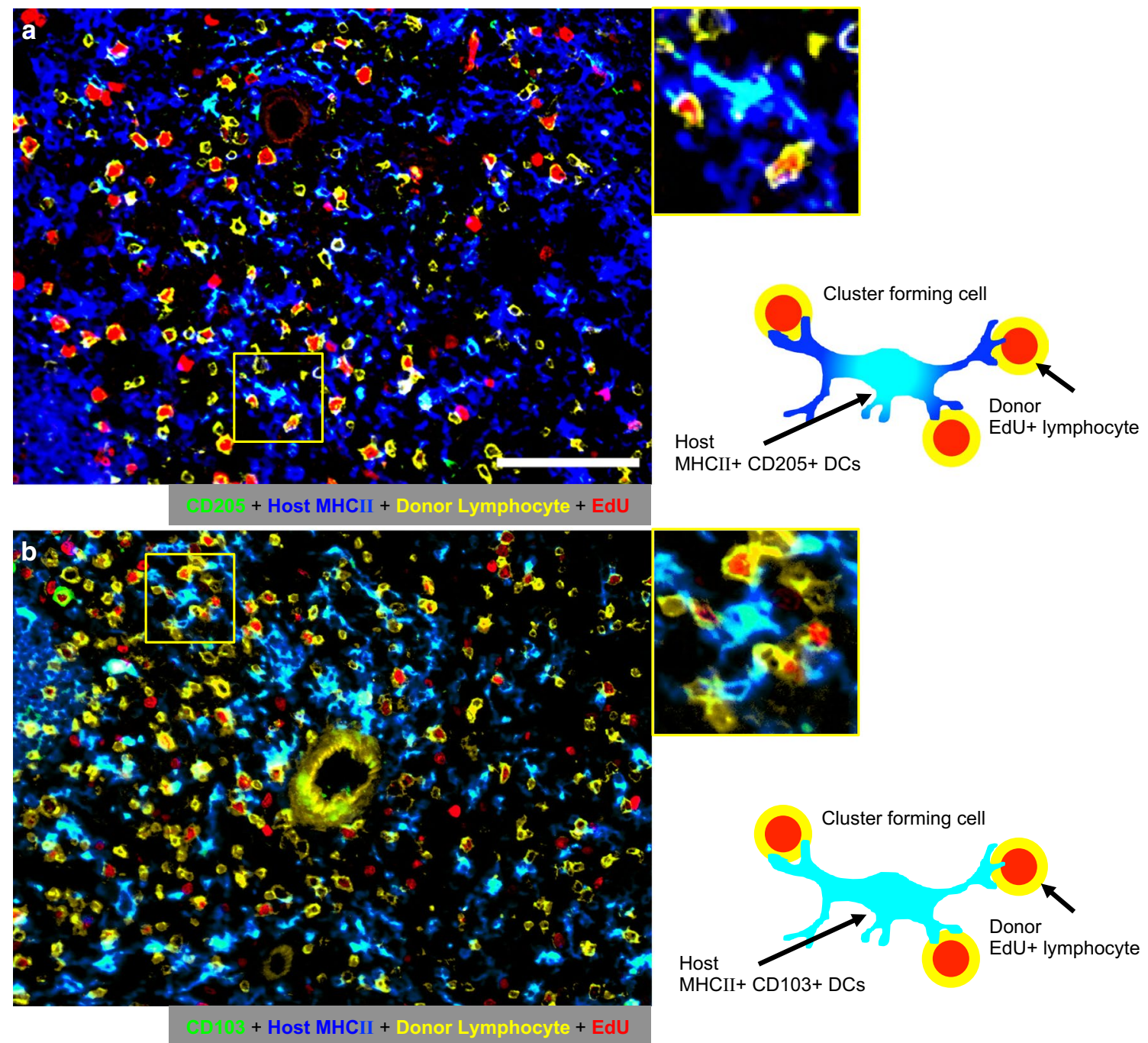

Fig. 7 Cluster formation of host DCs with $\mathrm{EdU}^{+}$proliferating donor lymphocytes. Four-color immunofluorescence staining of the spleen of day 2 after GvHR induction for host MHCII (Alexa-647-conjugated mAb, blue), CD205 or CD103 (Alexa-594-conjugated mAb, green), donor lymphocytes (indirect staining with Alexa-350-conjugated anti-mouse IgG, yellow) and EdU (Alexa-488-conjugated azide, red). Pseudocolors were assigned using AxioVision software. Scale

\section{Parallel analysis of FCM and immunohistology}

Flow cytometry (FCM) analysis indicated that cycling S-phase cells could be detected by EdU staining at a higher signal-to-noise ratio due to click chemistry (Salic and Mitchison 2008) than ordinary BrdU staining that requires an antigen-antibody reaction. EdU staining also has enabled the parallel examination of the proliferative response of activated cells both by immunohistology of tissue sections and by FCM of cells derived from the same lymphoid organs of one animal. Thus, the immunoproliferative response was examined qualitatively by bar $100 \mu \mathrm{m}$. Merged images are explained schematically in the right side of the panels. Note host $\mathrm{MHCII}^{+}$cells that cluster with donor proliferating cells (yellow cells with red nuclei) possess DC markers, $\mathrm{CD}_{205^{+}}$(a) and $\mathrm{CD}_{103}{ }^{+}$(b) (light blue, white arrow). Central yellow ring in $\mathbf{b}$ is the central artery, which emits nonspecific fluorescence

immunohistology of tissue sections, which then could be quantitated by FCM.

In this way, we could demonstrate not only the dose response of Tregs to CD28SA (Figs. 1, 2), but also the time kinetics and quantification of donor T-cell migration and proliferation in the GvHR (Fig. 4). In addition, some nuclear transcription factors detected by immunohistology were also detected by FCM and some proliferating cell subsets could be further isolated and used for RT-PCR analysis. Accordingly, this method can become a powerful tool for the objective and precise analysis of cellular interactions during the immune response in situ. 


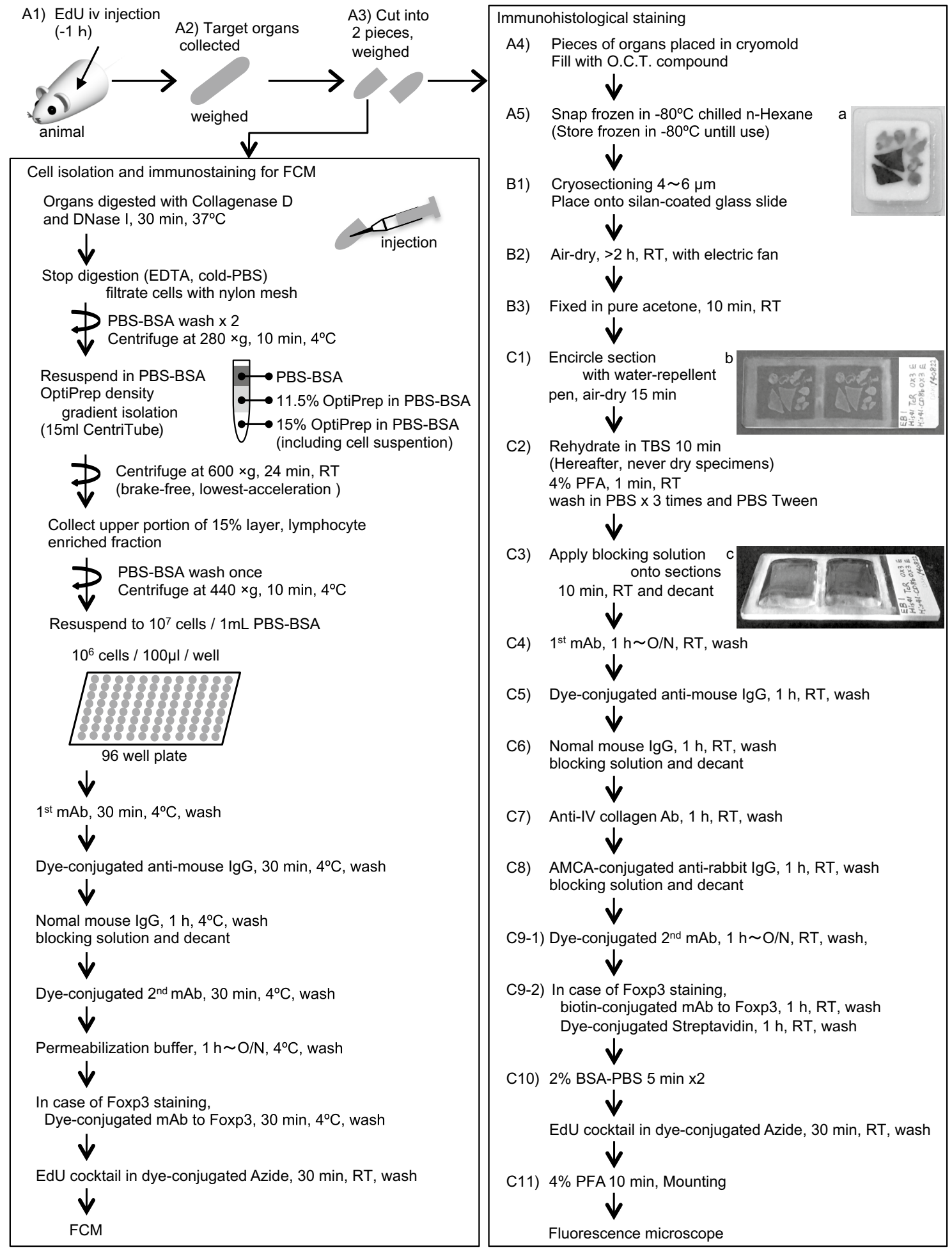

Fig. 8 A flow diagram of sequential steps for the present method. $A 1-A 5, B 1-B 3$, and $C 1-C 11$ correspond to the numbers in detailed working protocols described in supplemental materials

\section{Recommended protocols}

A flow diagram of sequential steps for the present method is illustrated in Fig. 8. Detailed working protocols with practical notes are described in supplemental online materials. To decrease the immunostaining steps, two mAbs of different species can be mixed and incubated simultaneously and then detected by a cocktail of secondary 
conjugates. Also, two different mAbs directly conjugated with different fluorochromes can be mixed.

\section{Conclusion}

We have demonstrated a newly developed method that enables the functional time-kinetic analysis of immunoproliferative responses in vivo, including activation, proliferation, and cellular interactions in a distinct domain of the lymphoid organs, which are quantitatively confirmed by FCM. RT-PCR of proliferating cells can be analyzed further. This method is as easy and reproducible as standard immunofluorescence methods and would be applicable not only for the immune response but also for other studies examining cell and tissue growth, such as hematopoiesis and organogenesis.

Acknowledgments This work was supported by JSPS KAKENHI Grant Number 24790200 (Grant-in-Aid for Scientific Research (S)) and a Dokkyo Medical University Investigator-Initiated Research Grant Number 2010-1-5. The authors appreciate the excellent technical support provided by Junko Sakumoto, Keiko Sasaki, Yasuko Nonaka, and Yoko Yamada. The authors also thank Drs. Frans Kroese and Yoshikazu Sado for donating His41 mAb and anti-mouse type IV collagen Ab, respectively, and Dr. Hiromich Tsurui for advising the filter combination of the fluorescence microscope and Dr. Xiaokang Li for valuable discussion concerning effects of CD28SA and Foxp3 response.

Conflict of interest The authors declare that they have no conflicts of interest.

Open Access This article is distributed under the terms of the Creative Commons Attribution 4.0 International License (http://creativecommons.org/licenses/by/4.0/), which permits unrestricted use, distribution, and reproduction in any medium, provided you give appropriate credit to the original author(s) and the source, provide a link to the Creative Commons license, and indicate if changes were made.

\section{References}

Beyersdorf N, Hanke T, Kerkau T, Hunig T (2005) Superagonistic anti-CD28 antibodies: potent activators of regulatory $\mathrm{T}$ cells for the therapy of autoimmune diseases. Ann Rheum Dis 64(Suppl 4):91-95. doi:10.1136/ard.2005.042564

Diermeier-Daucher S, Clarke ST, Hill D, Vollmann-Zwerenz A, Bradford JA, Brockhoff G (2009) Cell type specific applicability of 5-ethynyl-2'-deoxyuridine (EdU) for dynamic proliferation assessment in flow cytometry. Cytometry Part A : J Int Soc Anal Cytol 75:535-546. doi:10.1002/cyto.a.20712

Gottschalk RA, Corse E, Allison JP (2012) Expression of Helios in peripherally induced Foxp3 + regulatory $\mathrm{T}$ cells. J Immunol 188:976-980. doi:10.4049/jimmunol.1102964

Guo F, Ma J, McCauley E, Bannerman P, Pleasure D (2009) Early postnatal proteolipid promoter-expressing progenitors produce multilineage cells in vivo. J Neurosci: Off J Soc Neurosci 29:7256-7270. doi:10.1523/JNEUROSCI.5653-08.2009

Kampinga J, Kroese FG, Pol GH, Opstelten D, Seijen HG, Boot JH, Roser B, Nieuwenhuis P, Aspinall R (1990) RT7-defined alloantigens in rats are part of the leucocyte common antigen family. Scand J Immunol 31:699-710

Kitazawa Y, Fujino M, Li XK, Xie L, Ichimaru N, Okumi M, Nonomura N, Tsujimura A, Isaka Y, Kimura H, Hunig T, Takahara S (2009) Superagonist CD28 antibody preferentially expanded Foxp3-expressing nTreg cells and prevented graft-versus-host diseases. Cell Transplant 18:627-637

Matsuno K, Ezaki T, Kotani M (1989) Splenic outer periarterial lymphoid sheath (PALS): an immunoproliferative microenvironment constituted by antigen-laden marginal metallophils and ED2positive macrophages in the rat. Cell Tissue Res 257:459-470

Matsuno K, Ueta H, Shu Z, Xue-Dong X, Sawanobori Y, Kitazawa Y, Bin Y, Yamashita M, Shi C (2010) The microstructure of secondary lymphoid organs that support immune cell trafficking. Arch Histol Cytol 73:1-21

Park CG, Rodriguez A, Ueta H, Lee H, Pack M, Matsuno K, Steinman RM (2012) Generation of anti-human DEC205/CD205 monoclonal antibodies that recognize epitopes conserved in different mammals. J Immunol Methods 377:15-22. doi:10.1016/j. jim.2011.12.009

Saiki T, Ezaki T, Ogawa M, Maeda K, Yagita H, Matsuno K (2001) In vivo roles of donor and host dendritic cells in allogeneic immune response: cluster formation with host proliferating $\mathrm{T}$ cells. J Leukoc Biol 69:705-712

Salic A, Mitchison TJ (2008) A chemical method for fast and sensitive detection of DNA synthesis in vivo. Proc Natl Acad Sci U S A 105:2415-2420. doi:10.1073/pnas.0712168105

Sawanobori Y, Ueta H, Dijkstra CD, Park CG, Satou M, Kitazawa Y, Matsuno K (2014) Three distinct subsets of thymic epithelial cells in rats and mice defined by novel antibodies. Plos One 9:e109995. doi:10.1371/journal.pone.0109995

Ueta H, Shi C, Miyanari N, Xu XD, Zhou S, Yamashita M, Ezaki T, Matsuno K (2008) Systemic transmigration of allosensitizing donor dendritic cells to host secondary lymphoid organs after rat liver transplantation. Hepatology 47:1352-1362. doi:10.1002/ hep. 22161

Zhou S, Ueta H, Xu XD, Shi C, Matsuno K (2008) Predominant donor CD103 + CD8 + T cell infiltration into the gut epithelium during acute GvHD: a role of gut lymph nodes. Int Immunol 20:385-394. doi:10.1093/intimm/dxm153 